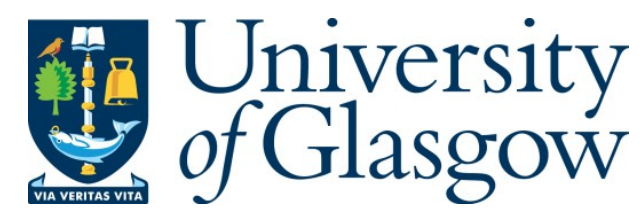

Torney, Clare, Lee, M artin R., and Owen, A lan W. (2014) Microstructure and growth of the lenses of schizochroal trilobite eyes.Palaeontology, 57 (4). pp. 783-799. ISSN 0031-0239.

Copyright $\odot 2013$ The Palaeontological A ssociation

A copy can be downloaded for personal non-commercial research or study, without prior permission or charge

Content must not be changed in any way or reproduced in any format or medium without the formal permission of the copyright holder(s)

When referring to this work, full bibliographic details must be given

http://eprints.gla.ac.uk/89974/

Deposited on: 28 J anuary 2014

Enlighten - Research publications by members of the U niversity of Glasgow http://eprints.gla.ac.uk 


\title{
MICROSTRUCTURE AND GROWTH OF THE LENSES OF SCHIZOCHROAL TRILOBITE EYES
}

by CLARE TORNEY ${ }^{1,2}$, MARTIN R. LEE ${ }^{1 *}$ and ALAN W. OWEN ${ }^{1}$

${ }^{1}$ School of Geographical and Earth Sciences, Gregory Building, Lilybank Gardens, Glasgow, Scotland, G12 8QQ, UK; e-mails: martin.lee@glasgow.ac.uk, alan.owen@glasgow.ac.uk ${ }^{2}$ Current address: Historic Scotland Conservation Directorate, 7 South Gyle Crescent, Edinburgh, EH12 9EB, UK; e-mail: Clare.Torney@scotland.gsi.gov.uk

*Corresponding author.

\begin{abstract}
Lenses within the schizochroal eyes of phacopine trilobites are made principally of calcite and characterisation of them using light microscopy and high-resolution electron imaging and diffraction has revealed an array of microstructural arrangements that suggest a common original pattern across the suborder. The low convexity lenses of Odontochile hausmanni and Dalmanites sp. contain calcite fibres termed trabeculae. The $c$ axis of trabecular calcite lies parallel to the lens axis, and adjacent trabeculae are distinguished by small differences in their $a$ axis orientations. Despite the common alignment, the boundaries between trabeculae cross-cut the $c$ axis as they fan out towards the lens base. Trabeculae are absent from the lens immediately beneath the visual surface and instead a radial fringe is present and is composed of micrometre-thick sheets of calcite whose $c$ axes are oriented at a low angle to the visual surface. High convexity lenses are more common than those of lower convexity among the species studied, and they have a much thicker radial fringe. Beneath this fringe all of the lens calcite is oriented with its $c$ axis parallel to the lens axis and it lacks trabeculae. We propose that both the high and low convexity lenses formed by rapid growth of calcite from a surface that migrated inwards from the cornea, and they may have had an amorphous calcium carbonate precursor. The trabeculae and radial fringes are unlikely to have had any beneficial effect on the transmission or focusing of light but rather are the outcomes of an elegant solution to the problem of how to construct a biconvex lens from a crystalline solid.
\end{abstract}

Key words: trilobite, phacopine, schizochroal eyes, microstructure, biomineralization, electron backscatter diffraction. 
THE in vivo internal structure, chemical composition and possible mode of functioning of the schizochroal eyes of the Lower Ordovician to Upper Devonian trilobite Suborder Phacopina have been the focus of considerable attention, and in recent years some controversy (e.g. Bruton and Haas 2003; Schoenemann 2007; Lee et al. 2007; Schoenemann and Clarkson 2008, 2011; Schoenemann et al. 2008; Torney et al. 2008, 2009). Schizochroal eyes are unique in the animal Kingdom (Fordyce and Cronin 1989, 1993; Clarkson 1997; Clarkson et al. 2006 and references therein) and the lenses of trilobite eyes, like the rest of the exoskeleton, were made principally from calcite. The birefringent properties of this mineral mean that all light rays entering the lenses, with the exception of those travelling parallel to the crystallographic $c$ axis of calcite, undergo double refraction. This phenomenon has important implications for using calcite in the construction of a visual system. Optical modelling of lenses in schizochroal eyes (e.g. Clarkson and Levi-Setti 1975; Gál et al. 2000; Bruton and Haas 2003) and determination of overall eye function (e.g. Cowen and Kelley 1976; Stockton and Cowen 1976; Schoenemann 2007) have all assumed that calcite had a uniform crystallographic orientation throughout the lenses. However even the early studies using transmitted light microscopy had shown that regions of the lenses differ in their crystallographic orientation (Towe 1973), and more recently it has been found that the lenses of many phacopine species are microstructurally complex (Bruton and Haas 2003; Torney et al. 2008, 2009). As lenses have also been extensively but variably diagenetically altered (Miller and Clarkson 1980; Lee et al. 2007, 2012) it is necessary to clarify their present-day microstructure so that their in vivo properties can be determined, and their growth and optical function can be properly understood. The new insights reported here have been enabled by the development of Electron Backscatter Diffraction (EBSD). This is a relatively new SEMbased technique for determining the crystallographic orientation of minerals at high spatial resolutions, and has already been applied with considerable success to understanding the growth and function of the shells of marine invertebrates (e.g. Dalbeck et al. 2006; Schmahl et al. 2009).

\section{SCHIZOCHROAL EYES}

Unlike the more common holochroal trilobite eyes that typically comprise a large number of small $(\sim 100 \mu \mathrm{m})$ lenses packed in direct contact with one another and overlain by a common cornea, schizochroal eyes contain fewer and larger $(\sim 0.2-1 \mathrm{~mm})$ lenses arranged in dorsoventral files and diagonal rows, separated by interlensar sclera (Clarkson et al. 2006). Each lens is covered by its own cornea, which plunges below the lens to form part of a cylindrical cavity, or capsule (Clarkson 1967; Bruton and Haas 2003), which is likely to have housed photoreceptive cells (e.g. Schoenemann et al. 2008). In some specimens the lenses are preserved as doublets with the curvature between the upper lens unit and the intralensar bowl interpreted as an aplanatic (blur-reducing) interface (Clarkson and Levi-Setti 1975).

Determination of lens chemical compositions in the specimen of Dalmanites studied by Clarkson and Levi-Setti enabled Lee et al. (2007) to postulate that the focusing of light was facilitated by concentration of magnesium into the intralensar bowl, thereby lowering its refractive index. A third component, the so called core, may also be present within such lenses (Clarkson et al. 2006 and Fig. 1), and could have been beneficial to image formation 
(Egri and Horvath 2012). Recent work by Lee et al. (2012) has shown that lenses in the schizochroal eyes of many phacopine species had an in vivo composition of $\sim 7.5$ mole\% $\mathrm{MgCO}_{3}$ (i.e. they were made from high-Mg calcite). High-Mg calcite bowls may therefore have been originally present in all lenses, but if so they are no longer recognisable in most specimens owing to redistribution and/or loss of magnesium during the diagenetic recrystallisation of high-Mg calcite to low-Mg calcite plus microdolomite (Lee et al. 2012).

Miller and Clarkson (1980) proposed that the constituent lenses of schizochroal eyes grew in a series of stages as an open-mesh construction of calcite sheets, or lamellae, each consisting of numerous fibres termed trabeculae. The crystallographic orientation of calcite within this mesh-work has been the matter of some debate. Each lens in the eye of Phacops [=Eldredgeops] rana was reported by Towe (1973) to consist of a polycrystalline corneal covering, in which the crystallographic $c$ axis of the radial crystals is perpendicular to the external lens surface, and a sub-corneal region that comprises a single calcite crystal with its crystallographic $c$ axis oriented parallel to the lens axis. Clarkson and Levi-Setti (1975) based their model of lens function on this uniform lens calcite orientation. However, Campbell (1975) showed that in addition to the two layers discussed by Towe (1973) the lenses of Eophacops, Paciphacops, Phacops and Reedops included an 'upper unit' (beneath the cornea) of variable thickness with changing $c$ axis orientation. Campbell concluded that the polycrystalline cornea probably had random rather than radial microstructure. More recently Bruton and Haas (2003) identified a radial upper unit in lenses of Geesops sparsinodosus similar to that described by Campbell (1975) and attributed the change in $c$ axis orientation to the presence of numerous small crystals. High-resolution mapping of the crystallographic orientation of lens calcite by EBSD has recently shown that two microstructurally distinct units occur beneath the cornea of Geesops sparsinodosus and Ananaspis macdonaldi (Torney et al. 2008, 2009): an upper 'radial fringe' and a lower lens region, corresponding to the upper unit and sub-corneal region as described by Campbell (1975) and Towe (1973) respectively.

Here we present new observations on the microstructure of schizochroal trilobite eyes made using light microscopy and a suite of electron imaging and diffraction techniques. By combining these new results with published work, we posit a model for lens growth and in vivo lens microstructure that will provide the basis for a re-evaluation of lens function.

\section{MATERIALS AND METHODS}

In the broader study of which this communication is part, we analysed the microstructures of the schizochroal eyes of 21 species of phacopine trilobites representing 13 genera covering a wide stratigraphical range and geographical distribution (Torney 2010; see also Table 1 in Lee et al. 2012). They therefore represent a wide spread of taxonomic groups and likely diagenetic histories. The specimens described and illustrated here are housed in the Hunterian Museum, University of Glasgow (numbers prefixed GLAHM), National Museums of Scotland (NMS) and Natural History Museum, London (NHMUK).

With the exception of the Dalmanites sp. thin sections originally described by Clarkson and Levi-Setti (1975), all thin sections used in this study were freshly prepared. Initially, epocure epoxy resin was applied to any exposed areas of the visual surface of the 
trilobite eye to provide a layer of protection and to minimise any subsequent damage, especially to the cornea. Large specimens and those held within a rock matrix were trimmed to a more manageable size prior to embedding, then the resin was poured into moulds within which specimens had been placed in the desired orientation. Once hardened, the resin blocks were ground using silicon carbide paper until the lenses were exposed. Blocks were mounted, exposed surface down, onto pre-ground glass slides using a small amount of epothin resin and placed in a press to set. Glass slides with sample blocks were sawn and ground to $\sim 50$ $\mu \mathrm{m}$ thickness, then ground further to $\sim 30 \mu \mathrm{m}$ using diamond lapping plates. Two stages of polishing using $1 \mu \mathrm{m}$ and $0.3 \mu \mathrm{m}$ alpha alumina preceded the final stage of polishing using $0.04 \mu \mathrm{m}$ colloidal silica solution.

The thin sections were made in two orientations relative to the eye: one with the plane of the thin section normal to the visual surface and so parallel to the lens axis (termed PLA, Fig. 2), and the other with the plane of the thin section normal to the lens axis (termed NLA). Most of the PLA thin sections were cut parallel to the palpebral lobe (termed 'horizontal', Fig. 2A) but some were made at an angle to the palpebral lobe and these orientations are referred to as 'diagonal' or 'intermediate' (Fig. 2B, C). The width and spacing of lenses seen in PLA thin sections will be determined by the orientation and positioning of the section in addition to the packing of lenses in the eye (Fig. 2).

All thin sections were studied initially in transmitted light, both plane polarized and between crossed polarizers, and in reflected light using a Zeiss Axioplan petrological microscope. Images were captured using a Nikon DN100 digital Net Camera. Secondary electron (SE) and backscattered electron (BSE) images were also obtained from carbon coated thin sections using a Quanta 200F field-emission SEM operated at $20 \mathrm{kV}$ and high vacuum. Information on the crystallographic orientation of calcite in the lenses, sclera and cements was then obtained by EBSD (e.g. Randle and Caul 2006; Prior et al. 1999) using a TSL-EDAX OIM 2000 system attached to the Quanta SEM. Most of the work was undertaken on uncoated thin sections (see Torney et al. 2009) with the SEM operated at low vacuum ( $\sim 50 \mathrm{~Pa}$ ). For the occasional high vacuum work the thin sections were coated with $2.5 \mathrm{~nm}$ carbon (Pérez-Huerta and Cusack 2009). Typical SEM operating conditions for EBSD were $20 \mathrm{kV}$ and a high beam current (beam currents are not quantified by this instrument) with the thin section tilted at $70^{\circ}$ towards the EBSD camera. Although scan parameters were varied according to factors such as size of the field of view, typically the system was run so that it acquired $\sim 10-20$ Kikuchi patterns/sec. at a step size of $\sim 0.1 \mu \mathrm{m}$. For all of the samples described here the Kikuchi patterns were indexed using structure files for calcite $(R \overline{3} \mathrm{c}$ : $\mathrm{a}=$ $0.4991 \mathrm{~nm}, \mathrm{c}=1.7062 \mathrm{~nm}, \beta=120^{\circ}$ ). The EBSD data were processed and presented using TSL OIM 5.2 software. Image quality (IQ) maps display the quality of the backscatter Kikuchi pattern using a greyscale (where black indicates very poor quality and white is good quality). Inverse pole figure (IPF) maps represent the crystallographic orientation of calcite whereby a colour coding indicates which lattice planes are oriented such that their poles (i.e. the plane normals) are parallel to a designated reference direction (Appendix S1). Tolerance maps show the angular deviation of all parts of a scanned area relative to a designated reference point on the map. The deviations are colour coded and the colour scale is shown 
next to the relevant image. The orientations of poles to specific lattice planes are also plotted on stereographic upper hemisphere pole figures.

Thin foils of parts of the lenses of Dalmanites sp. were prepared using the focused ion beam (FIB) technique for examination of their microstructures by TEM. The FIB work used a FEI Duomill operated at $30 \mathrm{kV}$. Following the procedure of Lee et al. (2003) 1000 nm thick foils were cut from the surface of the thin section using $\mathrm{Ga}^{+}$ions, then were welded to the tines of a copper support grid in-situ using electron- and ion-deposited platinum and finally milled to a thickness of $\sim 100 \mathrm{~nm}$. The copper grids were loaded into a double-tilt goniometer specimen holder then diffraction contrast images and selected area electron diffraction (SAED) patterns were obtained using a FEI T20 TEM operated at $200 \mathrm{kV}$.

Hitherto, the crystallographic orientation of trilobite lens calcite has been described with reference to the $c$ axis only, but the EBSD and TEM techniques used in the present study have enabled the investigation of other planes and directions (Appendix S1). The calcite $c$ axis has a Miller-Bravis index of $<0001>$ and is coincident with the pole to the $\{0001\}$ planes. The three $a$ axes are coincident with the poles to $\{2 \overline{1} \overline{1} 0\}$ planes and have MillerBravis indices of $\langle 2 \overline{1} \overline{1} 0>$. The $a$ axes lie normal to the $c$ axis as do the poles to $\{10 \overline{1} 0\}$ planes, also referred to as the mirror $(m)$ planes, which are coincident with $<10 \overline{1} 0>$. The $<4 \overline{13} 0>$ directions are normal to the $\{4 \overline{13} 0\}$ planes and the $c$ axis, and plot on the circumference of the stereogram approximately mid-way between $<10 \overline{1} 0>$ and $<2 \overline{1} \overline{1} 0>$ (Appendix S1). Within any one lens the crystallographic orientation of calcite varies, but most of it is oriented such that its $c$ axis is parallel to the lens axis and its $a$ axes bisect each of the surrounding six lenses (Fig. 2). The plane of horizontal PLA thin sections lies normal to one of the $a$ axes of lens calcite (Fig. 2B). In the diagonal orientation $<10 \overline{1} 0>$ is normal to the plane of the thin section (Fig. 2D) whereas the plane of intermediate PLA thin sections is approximately normal to $<4 \overline{13} 0>$ (Fig. 2C). The orientation of the thin sections will also determine the number and orientation of $\{10 \overline{1} 4\}$ cleavage planes and $\{\overline{1} 018\}$ e twin planes that may be observed within the lens calcite (Appendix S1).

\section{RESULTS}

With no living relatives of trilobites or close modern analogues for the schizochroal eye, the task of distinguishing in vivo lens microstructures from products of diagenesis must rely heavily on the identification of recurring features in different samples and on comparisons with the microstructures of the interlensar sclera, the cornea and early diagenetic cements. The orientation relationships between calcite in the lenses, and in the sclera, cornea and cements can also provide information on the mechanisms and relative timing of crystallisation of each of these features.

\section{Lens shape and microstructure}

The lenses examined can be divided into low and high convexity types. When viewed in plane polarized transmitted light, lenses of both types may be entirely turbid, entirely clear, or contain turbid and clear areas (Lee et al. 2012). In some cases these turbid and clear areas define the bowl and core (Fig. 1). The two lens shapes also correspond well with intralensar 
variations in crystallographic orientations as revealed by transmitted light microscopy (Fig. 3) and EBSD.

\section{Low convexity lenses}

In PLA thin sections these lenses are more oval than the high convexity ones and they occur in the eyes of Dalmanites sp. and Odontochile hausmanni. When viewed in transmitted light and between crossed polarizers most of the calcite in each lens extinguishes at the same point during rotation of the microscope stage (Fig. 3). There is however a very thin $(\sim 10-30 \mu \mathrm{m})$ band of sweeping extinction immediately beneath the visual surface of the lens, termed the 'radial fringe' by Torney et al. (2008). In lenses where the cornea has been preserved the radial fringe immediately underlies it.

EBSD shows that the $c$ axis of calcite beneath the radial fringe of low convexity lenses is composed of $\sim 1.5-8.0 \mu \mathrm{m}$ wide fibrous subgrains that correspond to the 'trabeculae' that have been identified previously using transmitted light (Clarkson et al. 2006, Schoenemann and Clarkson 2011) (Figs 1, 3, 4B). All of the trabecular calcite is oriented with its $c$ axis parallel to the lens axis (Fig. 4A), but calcite in adjacent trabeculae is misoriented by $\sim 2.0-2.5^{\circ}$ of rotation about the $c$ axis (Fig. 4C). Although trabecular boundaries appear planar in light microscope images and EBSD maps (Fig. 4B), higher magnification BSE images show that they have angular facets that are $\sim 2-4 \mu \mathrm{m}$ across (Fig. 5A). Micropores also occur along trabecular boundaries (Fig. 5A) and are responsible for the lines of turbidity that enable trabeculae to be identified using transmitted light (Fig. 1). TEM images of a foil that was cut from the trabeculae in Fig. 5A reveal that their boundaries are sharp but irregular and orientated parallel to one of the calcite $a$ axes (Fig. 5B). In most parts of the Dalmanites sp. lenses the boundaries between trabeculae are parallel to the lens axis, but they fan out, away from the lens axis, as they approach the lens base (Fig. 1). By contrast, trabeculae in Odontochile hausmanni lenses fan out from a point that is much closer to the visual surface (Fig. 4B). The bases of lenses in the Odontochile hausmanni sample have been overgrown by calcite cements that contain subgrains of the same size and crystallographic orientation as trabeculae (Fig. 4B). However, although trabecular boundaries make an angle of up to $40^{\circ}$ with the lens axis, the boundaries between cement subgrains lie parallel to the axis of the overlying lens and to the $c$ axis of their constituent calcite (Fig. 4B).

Trabeculae are absent from the radial fringe. The $c$ axis of radial fringe calcite lies at $90^{\circ}$ to the visual surface on the lens axis, but this angle progressively decreases to $\sim 60^{\circ}$ at the lens edge. Calcite in different parts of the radial fringe is related by rotation about an axis normal to the $c$ axis. In the intermediate PLA thin section of Odontochile hausmanni this rotation axis is coincident with $<4 \overline{1} \overline{3} 0>$ (Fig. 4D). TEM imaging of a foil cut through the Dalmanites sp. radial fringe shows that it is constructed from thin sheets of calcite that are reminiscent of the 'subconcentric laminae' described from the upper unit of Phacops [=Eldregeops] rana by Miller and Clarkson (1980). The boundaries between sheets are parallel to the trace of (0001) planes and to the visual surface of the lens (Fig. 6). 


\section{High convexity lenses}

These lenses have a much thicker radial fringe, which is represented by an area of sweeping extinction beneath the visual surface when the lens in thin section is rotated in transmitted light and between crossed polarizers (Fig. 3). Calcite beneath the radial fringe has a uniform crystallographic orientation, and during rotation of the microscope stage it extinguishes in step with the part of the radial fringe on the lens axis only (Fig. 3). Towe (1973) likewise described lenses containing radiating calcite crystals beneath the visual surface and an area of uniform extinction below. The thickness of the radial fringe is fairly consistent between lenses of the same species, reaching a maximum of half the lens depth in Eldregeops rana. A radial fringe also occurs in the lower parts of lenses of Boeckops boecki and some Barrandeops granulops, Geesops sparsinodosus, Phacops sp., Reedops cephalotes, Reedops cf. cephalotes and Reedops cf. sternbergi (Fig. 3). Miller and Clarkson (1980) described trabeculae in high convexity lenses of Phacops [=Eldregeops] rana that had been acid etched, but orientation tolerance EBSD maps of lenses of species including Eldregeops rana show that calcite beneath the radial fringe lacks such microstructures (Fig. 7C). Nonetheless the structures identified by Miller and Clarkson (1980) may provide an exception to our contention that all high convexity lenses lack trabeculae. Lenses are often overgrown by calcite cements that have adopted the crystallographic orientation of calcite at the lens base, whether it has a uniform orientation or a lower radial fringe (Fig. 3).

The $c$ axis of calcite within the upper radial fringe is oriented at $90^{\circ}$ to the visual surface on the lens axis and this angle decreases slightly to $\sim 80^{\circ}$ at the lens edge. In some specimens $c$ axis orientations vary steadily through the fringe (Fig. 7A, C) whereas in others the fringe is composed of $\sim 5-25 \mu \mathrm{m}$ sized subgrains whose boundaries are orientated approximately parallel to the calcite $c$ axis (Fig. 3). As the subgrains have a uniform orientation internally, the orientation of radial fringe calcite changes in a stepwise manner from the lens axis to lens edge. The upper radial fringe of species including Reedops cephalotes may contain curved lines that follow the profile of the visual surface, although becoming less convex downwards, and so correspond to the 'subconcentric laminae' described by Miller and Clarkson (1980, figure 2) and the 'growth lines' described by Bruton and Haas (2003). The crystallographic orientation of calcite in different parts of the radial fringe is related by rotation about a direction that is normal to the $c$ axis and in any one lens this rotation axis lies normal to the plane of the thin section. For example the rotation axis is $<2 \overline{1} \overline{1} 0>$ in the horizontal PLA thin section of Geesops schlotheimi (Fig. 7).

The three-dimensional microstructure of the radial fringe is revealed clearly in the NLA thin sections. They show that the $c$ axis of radial fringe calcite fans away from the lens axis and in all directions (Fig. 8A). The EBSD map in Figure 8A also shows that the radial fringe has a rough concentric structure, which is highlighted by the crystal model overlays, and analogous concentric lamellae were also observed by Miller and Clarkson (1980) in Phacops [=Eldregeops] rana. The NLA thin sections also confirm that the orientation of calcite throughout the radial fringe can be described solely by rotation about directions normal to the $c$ axis because the poles to $\{2 \overline{1} \overline{1} 0\}$ planes (i.e. the $a$ axes) do not precess around the circumference of the pole figures (as would be expected if calcite in the radial fringe calcite were related by rotation about the $c$ axis) (Fig. 8D). Towe (1973) showed that 
lenses in his 'tangential' thin sections (equivalent to NLA of the present study) display extinction crosses when viewed in transmitted light and between crossed polarizers, which is in agreement with the microstructure of the radial fringe as revealed by EBSD (Fig. 8).

\section{Microstructure of the interlensar sclera}

In all of the eyes examined, calcite of the sclera is less turbid than in the adjacent lenses and is composed of irregularly shaped crystals less than $5 \mu \mathrm{m}$ across. The sclera microstructures observed in PLA thin sections depend on the orientation in which they were prepared (Fig. 2). For example the eye of Odontochile hausmanni has been cut in an intermediate PLA orientation such that the lenses are widely spaced in the thin section and the sclera has a uniform microstructure (Fig. 4A). The $c$ axes of the constituent calcite crystals are oriented approximately normal to the upper and lower surfaces of the sclera, and orientation differences within the sclera are produced mainly by rotation about the calcite $c$ axis and with a smaller component of rotation about axes normal to $c$. The horizontal PLA thin section of Geesops schlotheimi (Fig. 9) has cut the eye so that lenses are closely spaced and two microstructurally distinct parts of the sclera can be recognised, namely a scleral pillar and an alveolar ring (see also Miller and Clarkson 1980, fig. 3A). The scleral pillar is parallel-sided, protrudes above the visual surfaces of adjacent parts of the lenses and below their bases. The $c$ axes of constituent calcite crystals show some variation in orientation but all lie parallel or at a low angle to the axes of the adjacent lenses. The alveolar ring lies between the scleral pillar and the edges of the adjacent lenses, and the $c$ axes of its constituent calcite crystals are oriented at a high angle to that of calcite in the lenses and scleral pillar (Fig. 9).

\section{Microstructure of the cornea}

The cornea is rarely seen in thin section, which in most cases is probably due to its loss during sample preparation. At least part of the cornea is preserved in a thin section of Barrandeops forteyi (Fig. 10A): it is $\sim 6 \mu \mathrm{m}$ thick and composed of calcite crystals $\sim 1.5-2.0$ $\mu \mathrm{m}$ across (Fig. 10B). The three layers of the cornea that were described by Miller and Clarkson (1980) have not been observed in the specimens examined. Pole figures of calcite in the cornea and in the lens immediately beneath it show that the $c$ axes of corneal crystals lie approximately parallel to the lens axis, although their orientations are much less tightly constrained than for lens calcite (Fig. 10C, D). The constituent crystals of the cornea show continuous variation in $a$ axis orientations so that they are related principally by rotation about the $c$ axis (Fig. 10D).

\section{DISCUSSION}

\section{Preservation of original lens microstructures}

Miller and Clarkson (1980) found that lenses in the schizochroal eyes of Phacops [now Eldredgeops] rana are susceptible to diagenetic alteration, which in some cases can obliterate their original microstructures. They hypothesized that this diagenetic instability may have been due to a high-Mg calcite composition in vivo, and this was verified by the discovery of microdolomite-rich calcite after high-Mg calcite within Dalmanites sp. lenses (Lee et al. 2007). Although Lee et al. (2007) considered only Dalmanites sp., the lenses of all of the 
phacopine species studied by Torney (2010) and Lee et al. (2012) were found to have contained high-Mg calcite in vivo. They showed that the original high-Mg calcite had recrystallized to calcite plus microdolomite by very fine-scale dissolution-reprecipitation, and a by-product of this reaction is the micropores that give lenses their optical turbidity. The sclera and the rest of the cuticle are free of microdolomite, which is consistent with an original low-Mg calcite composition (see Wilmot and Fallick 1989; Lee et al. 2012), and explains their lower susceptibility to recrystallisation.

The lenses examined in the present study are inferred to have largely retained their in vivo microstructures despite recrystallisation because essentially identical microstructures are seen in lenses of different taxa from localities on different continents. This applies especially to the high convexity lenses, such as those of Geesops, but even though only two species were studied whose eyes have low convexity lenses, the thin upper radial fringe and trabeculae are common to both species, and were also found in all analysed lenses of both specimens. There is, however, likely to have been a variation in the degree of diagenetic coarsening of original microtextures. This is particularly evident within the radial fringe of different specimens of Geesops schlotheimi whereby the $c$ axis orientations may vary uniformly or in a stepwise fashion from the lens axis to the lens edge (Fig. 3). The uniform variation is inferred to be closest to the original microstructure, with subgrains developing by coarsening during recrystallization.

Calcite cements have adopted the crystallographic orientation of the lens or sclera calcite crystals on which they nucleated (Fig. 4A, B). The timing of cementation relative to the burial history of the rock cannot be determined in most cases, although cements in some samples contain micrometre-sized dolomite crystals indicating that they were originally high$\mathrm{Mg}$ calcite and so must have crystallized from marine pore waters during early diagenesis (Lee et al. 2012). In the case of the Odontochile hausmanni specimen, the syntaxial cements contain subgrains of identical size, shape and crystallographic orientation to the trabeculae at the base of the lens (Fig. 4B), thus demonstrating that the trabeculae were present prior to cementation. Crucially however the boundaries between cement subgrains lie parallel to the calcite $c$ axis (and to the lens axis), whereas the boundaries between trabeculae on which the cements have nucleated lie at up to $40^{\circ}$ to the $c$ axis of their constituent calcite (Fig. 4). This difference in the crystallographic orientation of subgrain boundaries between the lens and cement demonstrates that the trabeculae grew under a biological control that was able to override the inorganic preference of calcite fibres (as shown by the cement) to align their boundaries parallel to the $c$ axis.

\section{Mechanisms of lens crystallisation}

Most of the examined phacopine species, typified by the specimens of Geesops, have strongly convex lenses with a thick upper radial fringe, a lower lens unit of uniform crystallographic orientation that lacks trabeculae, and in some species also a lower radial fringe. Only the eyes of Dalmanites sp. and Odontochile hausmanni have lenses of low convexity that contain a very thin radial fringe along with downward fanning trabeculae. Here we develop the 'locking crystallization model' for the growth of these biconvex crystalline lenses. This model draws on the finding by Miller and Clarkson (1980) that the 
lenses of Phacops [=Eldgregeops] rana grew from the cornea towards the lens base, starting as a cone on the lens axis that progressively widened and thickened to eventually form the bowl.

The locking crystallization model assumes that the $c$ axes of growing calcite crystals were oriented normal to a crystallisation surface that was advancing from the cornea. This would also mean that calcite $a$ axes would lie in the plane of the crystallisation surface. In common with the Miller and Clarkson (1980) model the rate of advancement of this surface towards the lens base is assumed to have decreased progressively from a maximum on the lens axis to close to zero at the lens edge so that it had a convex profile during crystallization of the upper half of the lens (Fig. 11B) and a concave profile during crystallization of the lower half. If the cornea was present before the lens started to crystallize, the transition from corneal to lens calcite must have been accompanied by a tightening of $c$ axis orientations and a change from continuously varying to fixed $a$ axis orientations. It is unknown how the $a$ axis orientation was 'selected' from the range of orientations in the cornea, and how this 'information' was communicated between lenses so that they could all crystallize calcite with the same $a$ axis orientations. Notably however the orientation of calcite in the scleral pillar is better constrained than in the adjacent lenses (Fig. 9), and so could have served as a template.

Once calcite on any one part of the crystallisation surface became oriented with its $c$ axis parallel to the lens axis, that part of the lens is suggested to have become 'orientation locked' (i.e. the calcite crystal structure was continuous, or 'coherent' over that part of the crystallisation surface). Note that if the calcite $a$ axes had a common orientation over the entire crystallisation surface from the outset, locking would have required alignment of $c$ axes only. This process of 'orientation locking' started at the junction of the lens axis with the visual surface then expanded radially outwards and towards the lens base as the calcite lens thickened (Fig. 11C). The lower boundary of the radial fringe therefore delineates the interface between 'unlocked' and 'locked' calcite, and here is called the 'locking contour' (Fig. 11). By the time the crystallisation surface reached the centre of the lens it was planar, oriented normal to the lens axis, and orientation locking had been achieved along its entire length. The lower radial fringe can easily be accounted for by 'unlocking' of calcite along the most highly curved parts of the concave crystallisation surface as it approached the lens base. The 'growth lines' seen in some samples therefore delineate the former location of the crystallisation surface.

The locking crystallisation model can also account for the much thinner radial fringe of the low convexity lenses. In the first formed parts of these lenses the calcite $c$ axis was initially oriented at a much shallower angle to the visual surface than the $\sim 80-90^{\circ}$ of the high convexity lenses (Fig. 11B) so that orientation locking was achieved by the time that the calcite was only a few tens of micrometers thick and the radial fringe produced is thin. Although the $a$ axes of calcite within the trabeculae are slightly misoriented across trabecular boundaries throughout the lens, the $c$ axes beneath the radial fringe are parallel so that orientation locking could have been achieved by common alignment of (0001) planes over the crystallisation surface but without coherency of the $\{2 \overline{1} \overline{1} 0\}$ planes. The outwards fanning of trabeculae can also be accounted for by the locking crystallisation model if the boundaries between trabeculae were oriented normal to the crystallization surface, which would have 
become increasingly concave towards the lens base. However in contrast to the lower radial fringe of the high convexity lenses, the (0001) planes of trabecular calcite remained 'locked' throughout the whole thickness of the lens beneath the radial fringe.

The process of calcite crystal growth is unknown with respect to trilobite lenses, and specifically whether the calcite was secreted by tissues or formed by crystallisation of an amorphous precursor. The latter possibility is suggested by analogy with millimetre-sized granules of calcite that are secreted by earthworm Lumbricus terrestris (Lee et al. 2008). These granules form initially as aggregates of amorphous calcium carbonate (ACC), then as they travel through the earthworm in the process of being secreted the ACC crystallizes to calcite with a radial-fibrous microstructure that is reminiscent of the subgrained radial fringes (Lee et al. 2008). Although granule microstructures formed by crystallisation radially outwards from a central nucleus such as a quartz grain (as opposed to crystallisation inwards from the cornea as hypothesised here for schizochroal lenses), it is clear that microstructures similar to those found in high convexity trilobite lenses can form by crystallisation of ACC and even without any direct biological control. It is also pertinent to note that these granules are commonly zoned with respect to magnesium concentrations so providing an analogy with the magnesium-rich bowl of Dalmanites sp. (Lee et al. 2007), and they crystallize within a matter of hours (Lee et al. 2008). Such rapid lens crystallisation would be essential for the trilobites in order to minimise the amount of time between moults when they were effectively blind.

\section{Implications for lens optics}

Results of this study suggest that the principal intralensar microstructures of phacopine trilobite lenses, namely the trabeculae, radial fringe(s) and uniformly oriented calcite, were present in vivo, and their properties can be readily explained by locking crystallisation. Although these microstructures are interpreted to be the by-product of growing a biconvex crystalline lens, below we explore whether they were also beneficial for lens optics.

Schoenemann and Clarkson (2011) proposed a new model for the in vivo internal structure and function of the lenses of some phacopine species. They suggest that trabeculae served as optical fibres to guide light from the visual surface to an array of photoreceptors beneath the lens. This is an alternative to the aplantic doublet model of Clarkson and LeviSetti (1975), but the two are not necessarily mutually exclusive as light guide trabeculae could have operated in tandem with the doublet. The light guide model requires that each trabecula/optical fibre was enclosed in an organic sheath that would have contained the light as it travelled towards photoreceptors beneath. Results from the present study agree with Schoenemann and Clarkson (2011) and previous workers (e.g. Clarkson (1979) and Miller and Clarkson (1980)) that the trabeculae were present in vivo and formed during lens crystallization, although they are generally seen only in the low convexity lenses. The hypothesis of Schoenemann and Clarkson (2011) that trabeculae were contained within an organic sheath is difficult to test directly because although interfaces between trabeculae are very sharp, as evidenced by TEM (e.g. Fig. 5B), any organic material that may once have been present has been lost by decay. 
Two observations from the present study question the applicability of the light guide model, at least to the species with low convexity lenses that were studied here. The first is that trabeculae never meet the visual surface, which would be required if each were to collect light incident on their end. Instead there is a radial fringe immediately beneath the visual surface so that each of the 'optical fibres' would collect light falling on an area of the visual surface greater than its diameter owing to scattering by the radial fringe. This would have the effect of 'defocusing' the image formed by the photoreceptors, although in low convexity lenses where the radial fringe is very thin it may have had a negligible effect on the overall image quality. The second observation concerns the arrangement of the trabeculae within the lens. The EBSD orientation tolerance mao of Odontochile hausmanni shows clearly that the trabeculae fan out from a point close to the intersection of the lens axis with the visual surface (Fig. 4B). In the model of Schoenemann and Clarkson (2011) light can enter trabeculae only from their ends and so in Odontochile hausmanni just the small proportion of trabeculae around the lens axis would be able to collect and transmit light. Although observations of the present study neither prove or disprove the light guide model, without strong evidence that trabeculae were originally enclosed within organic sheaths we conclude that the doublet model of Clarkson and Levi-Setti (1975) remains the best description of low convexity lens function.

As the $c$ axis of calcite within the radial fringe of high convexity lenses is oriented approximately normal to the visual surface, it is tempting to suggest that these microstructures were optimised for the transmission of non-birefringent light to the lens interior. However, ray tracing experiments show that only paraxial light incident on the visual surface in the vicinity of the lens axis would have travelled through the lens without undergoing double refraction (Torney 2010). These findings further support the contention that radial fringe microstructures are growth related rather than functional. Bruton and Haas (2003) speculated that the 'growth lines' within lenses formerly contained organic films, whose graded density through the lens served to focus light via their impact on refractive index. Although there is no evidence in the present study to challenge this 'gradient index' model, we note that although the growth lines are most likely to be original features of the lenses, they delineate the former position of the crystallisation surface (Fig. 11). Thus as the name suggests they are growth related rather than functional.

\section{CONCLUSIONS}

We conclude that the microstructures of lenses in the schizochroal eyes of phacopine trilobites can be accounted for by crystallization of calcite along a surface migrating from the cornea to the lens base. This microstructural pattern appears to be applicable across the Suborder Phacopina and the thickness of the radial fringe is linked to lens curvature and so is taxonomically controlled within the subfamily. By analogy with earthworm granules, the lens calcite could have formed from an amorphous calcium carbonate precursor in a matter of hours, thus minimising the duration of time that the animal was blind. Now that in vivo lens microstructures have been precisely determined, light transmission through the lenses can be accurately modelled, including accounting for the impact of double refraction, which is determined by local $c$ axis orientations. 
Acknowledgements. We thank Peter Chung for help with the SEM and EBSD, and Billy Smith and Colin How (School of Physics and Astronomy, University of Glasgow) for assistance with the FIB and TEM work. We are also grateful to Euan Clarkson and Alan Thomas for their very helpful comments on an earlier version of this manuscript. We thank the following for providing the specimens on which this work was based and/or within whose institutions the material is now housed: David Bruton (University of Oslo), Petr Budil (Czech Geological Survey), Brian Chatterton and Ryan McKellar (University of Alberta), Neil Clark (Hunterian Museum, University of Glasgow), Euan Clarkson (University of Edinburgh), Richard Fortey and Claire Mellish (Natural History Museum, London), Christian Klug (Museum der Universität Zürich), David Rudkin (Royal Ontario Museum), Brigitte Schoenemann (Universität Bonn) and Sarah Stewart (National Museums Scotland). The Leverhulme Trust is thanked for funding this research project through Research Grant F/07 179/AM.

\section{SUPPORTING INFORMATION}

Additional supporting information can be found in the online version of this article:

Appendix S1. Upper hemisphere stereographic projection of calcite for interpretation of EBSD maps and pole figures, ad TEM electron diffraction patterns. 


\section{REFERENCES}

BRUTON, D. L. and HAAS, W. 2003. The puzzling eye of Phacops. Special Papers in Palaeontology, 70, 349-361.

CAMPBELL, K. S. W. 1975. The Functional Anatomy of Phacopid Trilobites: Musculature and Eyes. Journal and Proceedings, Royal Society of New South Wales, 108, 168-188.

CLARKSON, E. N. K. 1967. Fine structure of the eye in two species of Phacops (Trilobita). Palaeontology, 10, 603-616.

- 1975. The evolution of the eye in trilobites. Fossils and Strata, 4, 7-31.

and LEVI-SETTI, R. 1975. Trilobite eyes and the optics of Des Cartes and Huygens. Nature, 254, 663-667.

1979. The visual system of trilobites. Palaeontology, 22, 1-22.

1997. The eye: morphology, function and evolution. 114-132. In KAESLER, R. L.

(ed) Treatise on invertebrate paleontology. Part O. Arthropoda 1, Trilobita revisited.

Geological Society of America, Boulder and University of Kansas Press, Lawrence, $530 \mathrm{pp}$.

-_-_-_ LEVI-SETTI, R. and HORVATH, G. 2006. The eyes of trilobites: The oldest preserved visual system. Arthropod Structure and Development, 35, 247-259.

COWEN, R. and KELLEY, J. S. 1976. Stereoscopic Vision within Schizochroal Eye of Trilobites. Nature, 261, 130-131.

DALBECK, P., ENGLAND, J., CUSACK, M., LEE, M. R. AND FALLICK, A. E. 2006. Crystallography and chemistry of the calcium carbonate polymorph switch in M. edulis shells. European Journal of Mineralogy, 18, 601-609.

EGRI, A. AND HORVATH, G. 2012. Possible optical functions of the central core in lenses of trilobite eyes: spherically corrected monofocality or bifocality. Journal of the Optical Society of America A-Optics image, 29 (9), 1965-1976.

FORDYCE, D. and CRONIN, T. W. 1989. Comparison of Fossilized Schizochroal Compound Eyes of Phacopid Trilobites with Eyes of Modern Marine Crustaceans and Other Arthropods. Journal of Crustacean Biology, 9, 554-569. - and --_-_ 1993. Trilobite Vision - a Comparison of Schizochroal and Holochroal Eyes with the Compound Eyes of Modern Arthropods. Paleobiology, 19, 288-303.

GÁL, J., HORVÁTH, G., CLARKSON, E. N. K. and HAIMAN, O. 2000. Image formation by bifocal lenses in a trilobite eye? Vision Research, 40, 843-853.

LEE, M. R., TORNEY, C. and OWEN, A. W. 2007. Magnesium-rich intralensar structures in schizochroal trilobite eyes. Palaeontology, 50, 1031-1037. 2012. Biomineralization in the Palaeozoic oceans: Evidence for simultaneous crystallization of high and low magnesium calcite by phacopine trilobites. Chemical Geology, 314-317, 33-44.

BLAND, P.A. and GRAHAM, G. 2003. Preparation of TEM samples by focused ion beam (FIB) techniques: applications to the study of clays and phyllosilicates in meteorites. Mineralogical Magazine, 67, 581-592.

HODSON, M.E. and LANGWORTHY, G. 2008. Earthworms produce granules of intricately zoned calcite. Geology, 36, 943-946. 
MILLER, J. and CLARKSON, E. N. K. 1980. Post-Ecdysial Development of the Cuticle and the Eye of the Devonian Trilobite Phacops rana milleri Stewart 1927. Philosophical Transactions of the Royal Society of London Series B (Biological Sciences), 288, 461-480.

PÉREZ-HUERTA, A. and CUSACK, M. 2009. Optimising electron backscatter diffraction of carbonate biominerals - resin type and carbon coating. Microscopy and Microanalysis, 15, 197-203.

PRIOR, D. J., BOYLE, A.P., BRENKER, F., CHEADLE, M. C., DAY, A., LOPEZ, G., PERUZZO, L., POTTS, G. J., REDDY, S., SPIESS, R., TIMMS, N. E., TRIMBY, P., WHELER, J. and ZETTERSTROM, L. 1999. The application of electron backscatter diffraction and orientation contrast imaging in the SEM to textural problems in rocks. American Mineralogist, 84, 1741-1759.

RANDLE, V. and CAUL, M. 1996. Representation of electron backscattered diffraction data. Materials Science and Technology, 12, 844-850.

SCHMAHL, W. W., GRIESSHABER, E., NEUSER, R. D., GOETZ, A. and LUETER, C. 2009. Electron Backscatter Diffraction Study of Brachiopod Shell Calcite - Microscale Phase and Texture Analysis of a Polycrystalline Biomaterial. Particle and Particle Systems Characterisation 25, 474-478.

SCHOENEMANN, B. 2007. Trilobite eyes and a new type of neural superposition eye in an ancient system. Palaeontographica Abteilung A - Palaozoologie-Stratigraphie, 281, 63-91.

- and CLARKSON, E. N. K. 2008. Did The trabecula in phacopid lenses act as lightguides? 351-354. In RÁBANO, I., GOZALO, R. and GARCÍA-BELLIDO, D. (eds) Advances in triobite research. Instituto Geológico y Minero de España, Madrid, 448 pp.

--_--- and CLARKSON, E. N. K. 2011. Light guide lenses in trilobites? Earth and Environmental Science Transactions of the Royal Society of Edinburgh, 102, 17-23.

--_-_- CLARKSON, E. N. K. and FRANZ, A. 2008. Sublensar capsules in phacopid eyes. 355-359. In RÁBANO, I., GOZALO, R. and GARCÍA-BELLIDO, D. (eds) Advances in triobite research. Instituto Geológico y Minero de España, Madrid, 448 pp.

STOCKTON, W. L. and COWEN, R. 1976. Stereoscopic vision in one eye: paleophysiology of the schizochroal eye of trilobites. Paleobiology, 2, 304-315.

TORNEY, C. 2010. Mineral eyes - lessons from the natural world. Unpublished PhD thesis, University of Glasgow.

----_- LEE, M. R. and OWEN, A. W. 2008. An Electron Backscatter Diffraction study of Geesops: A broader view of trilobite vision? 389-394. In RÁBANO, I., GOZALO, R. and GARCÍA-BELLIDO, D. (eds) Advances in triobite research. Instituto Geológico y Minero de España, Madrid, 448 pp.

2009. Peering into the eyes of Trilobites using EBSD. 619-626. In

ROLlETT, A. D. (ed) Applications of Texture Analysis: Ceramic Transactions. John Wiley and Sons, 836 pp.

TOWE, K. M. 1973. Trilobite Eyes: Calcified Lenses in vivo. Science, 179, 1007-1009. 


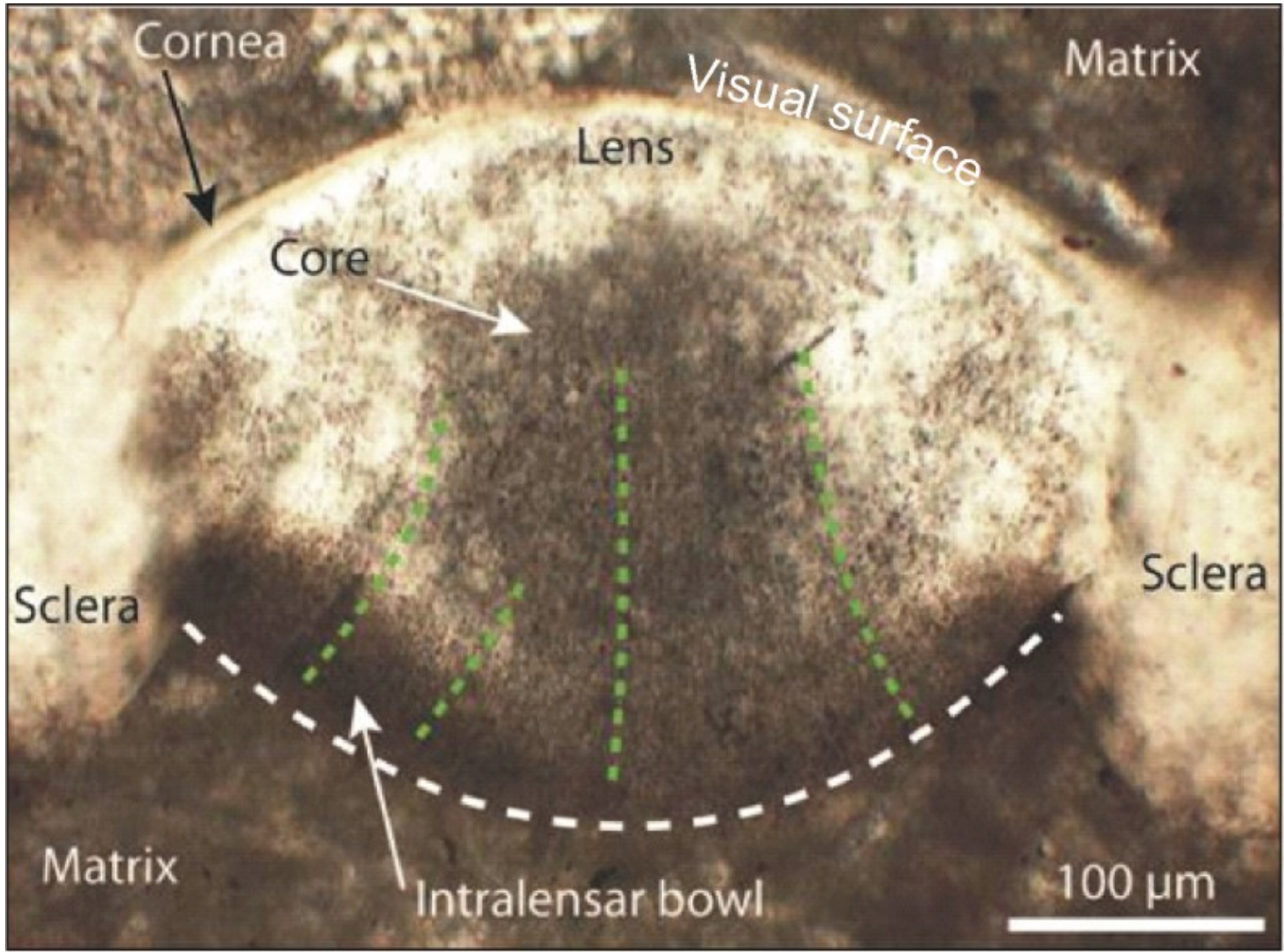

FIG. 1. Dalmanites sp GLAHM 152332, Silurian, locality not known. Plane polarized transmitted light image of a lens in an intermediate PLA thin section. The intralensar bowl and core are both visible by virtue of their greater turbidity than the rest of the lens and the sclera. Turbid calcite also highlights the trabeculae, which fan out towards the lens base. Some of the trabeculae are outlined by dashed green lines, and the lens base is marked by a dashed white line. The lens and sclera are enclosed within a limestone matrix. 

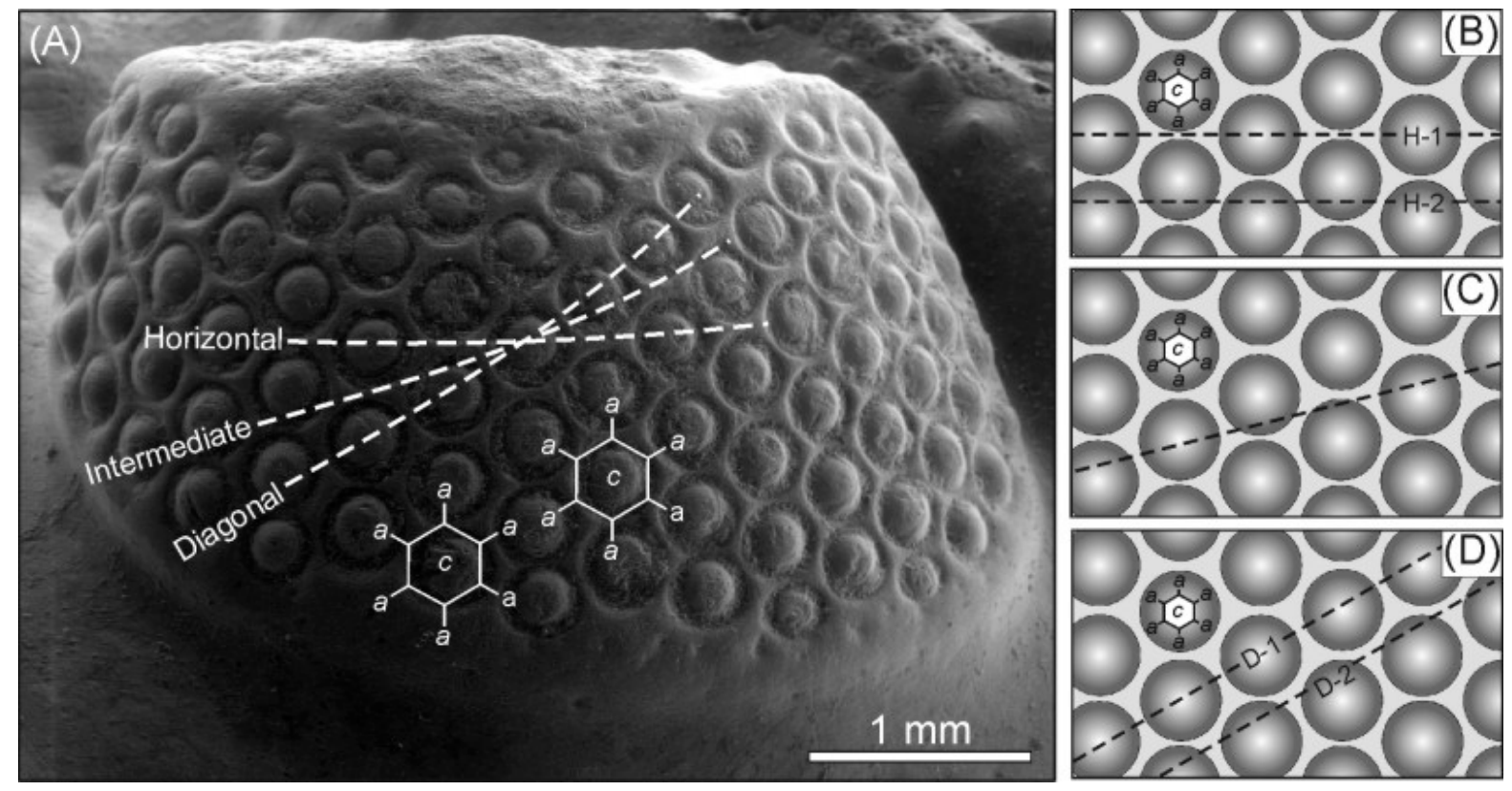

FIG. 2. Geesops schlotheimi (Bronn), GLAHM 152331, Ahrdorf Fm. (Eifelian), GeesGerolstein, Eifel, Germany. (A) Secondary electron SEM image of an eye on which the three PLA thin section orientations are indicated by dashed white lines. Also overlain on two of the lenses is the crystallographic orientation of calcite along the lens axis (N.B. the $c$ axis lies normal to the plane of the page). (B), (C) and (D) are schematic diagrams of the eye that illustrate how the spacing and apparent sizes of lenses and thickness of sclera (light grey) will depend on its position and orientation of the thin section. A horizontal thin section (B) will contain lenses of equal apparent size and one of the $a$ axes will be normal to the plane of the thin section. The apparent size of a lens will be greater where cut along its axis (H-1) than its edge (H-2). The intermediate thin sections (C) will contain lenses of different apparent sizes that are separated by variable amounts of sclera, and the pole to one of the $\{4 \overline{1} \overline{3} 0\}$ planes will be normal to the plane of the thin section. The diagonal thin sections (D) will contain lenses of equal apparent size and the pole to one of the $\{10 \overline{1} 0\}$ planes will be normal to the plane of the thin section. The apparent size of a lens will be greater where cut along its axis (D-1) than its edge (D-2). 

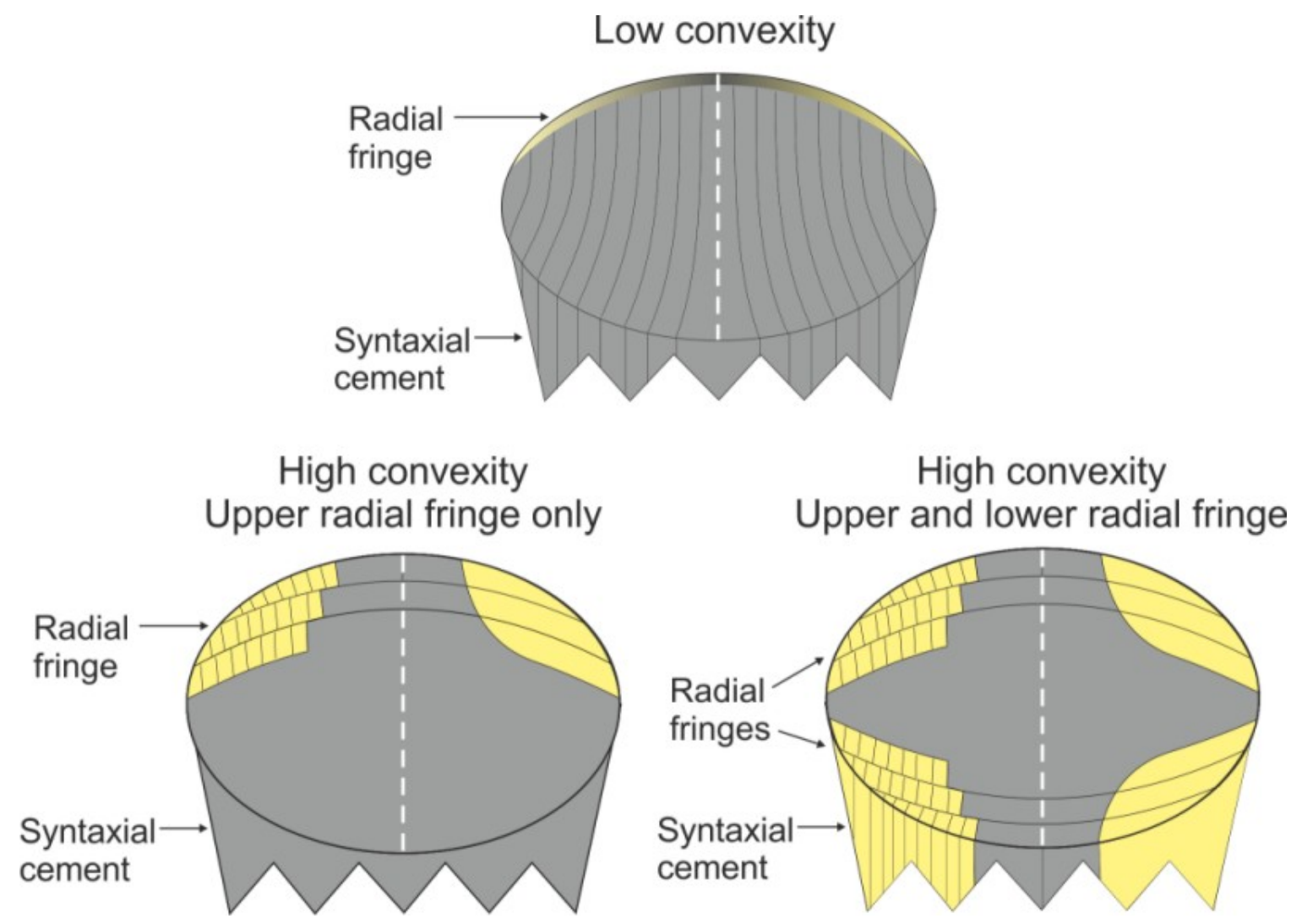

FIG. 3. Diagrams showing the properties of the three types of lenses as would be seen in a PLA thin section viewed in transmitted light and between crossed polarizers. Dark grey and yellow areas are calcite in and out of extinction respectively. The dashed white line is the lens axis, the curved black lines subparallel to the visual surface or lens base are growth lines. The narrow subvertical black lines within the low convexity lens are the boundaries between trabeculae, and can be traced into the syntaxial cements. The left hand sides of the two high convexity lenses show the appearance of the radial fringe where it contains subgrains whereas the right hand sides show the fringes without subgrains. The lenses typically have a thickness parallel to the lens axis of $\sim 0.2 \mathrm{~mm}$. 

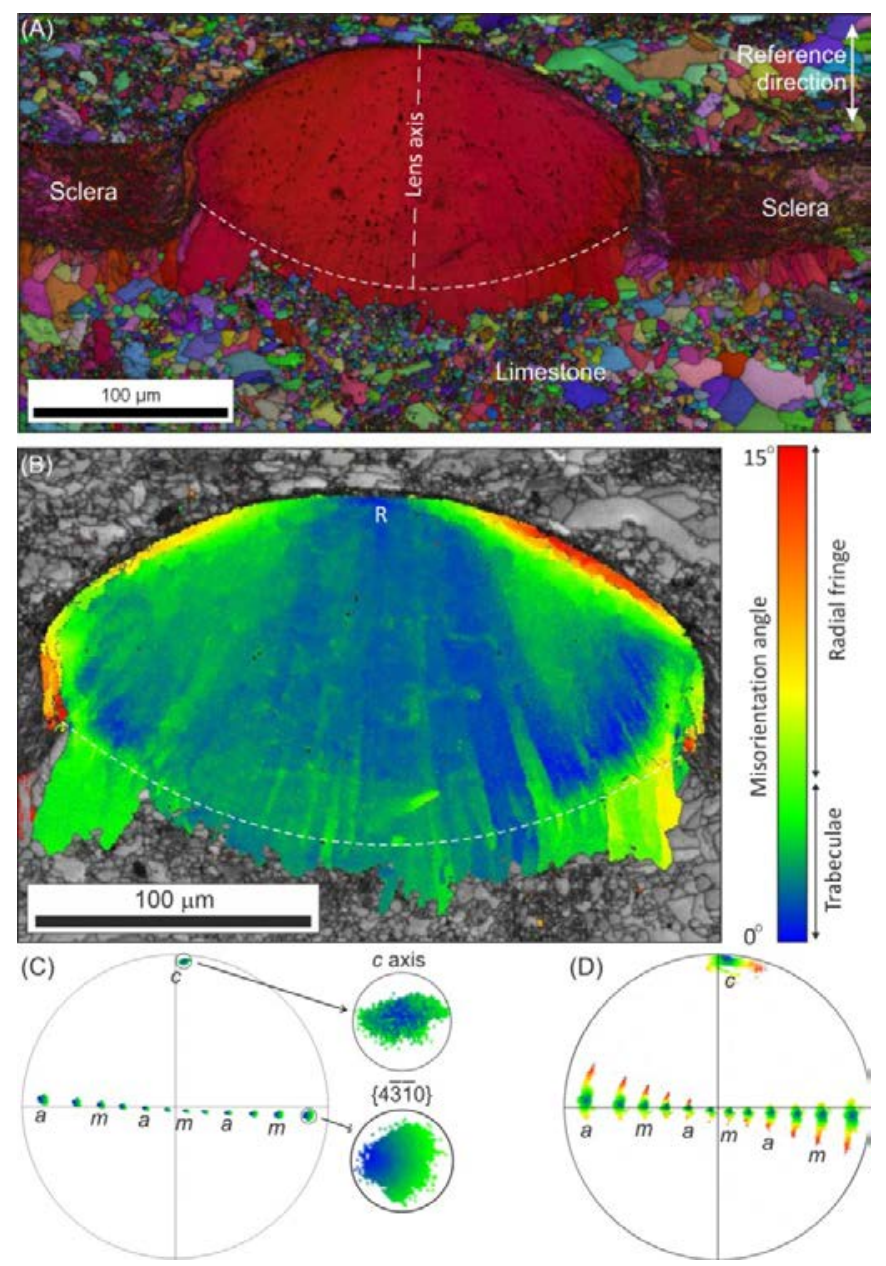

FIG. 4. Odontochile hausmanni (Brongniart), NMS.G. 1963.15.69, Dvorce-Prokop Limestone

(Lower Devonian), Bohemia. EBSD results from an eye in an intermediate PLA thin section. (A) An IPF map overlain on an IQ map. The IPF colour coding shows that all of the lens calcite is oriented with its $c$ axis parallel to the reference direction (and the lens axis). The base of the lens, which is outlined by a dashed white line, has been overgrown by calcite cements, as has the base of the sclera. (B) Orientation tolerance map of the lens in (A) overlain on an IQ map. All of the calcite in the lens and cement is within $15^{\circ}$ of the orientation of the reference point (R). Trabeculae are defined by small orientation differences producing alternating blue and green fibrous subgrains. The radial fringe is present immediately beneath the visual surface and its constituent calcite has the largest orientation difference from R. (C) Pole figure constructed from calcite in the central part of the lens in (B) and with the same colour coding. $c$ denotes the $c$ axis, $a$ denotes the $a$ axis, $m$ denotes the poles to $\{10 \overline{1} 0\}$ planes, and the unlabelled points are the poles to $\{4 \overline{1} \overline{3} 0\}$ planes. The two orientations of the trabeculae (coloured blue or green) are clearly distinguished within the points along the equator of the pole figure, whereas for the $c$ axis datapoint the two orientations are superimposed. The 'blue' datapoints record rotation of $\sim 2^{\circ}$ clockwise about the $c$ axis (relative to the image as printed) and the green datapoints record rotation of $\sim 2^{\circ}$ anticlockwise about the $c$ axis. Two of these datapoints are shown enlarged to the right of the pole figure. (D) Pole figure of the whole lens in (B) and using the same colour coding. Poles to the various planes are labelled as in (C). This pole figure shows that calcite within the radial fringe is related by rotation about an axis between $<10 \overline{1} 0>$ and $<4 \overline{1} \overline{3} 0>$, and this rotation is asymmetric and mainly clockwise relative to the EBSD map in (B). 

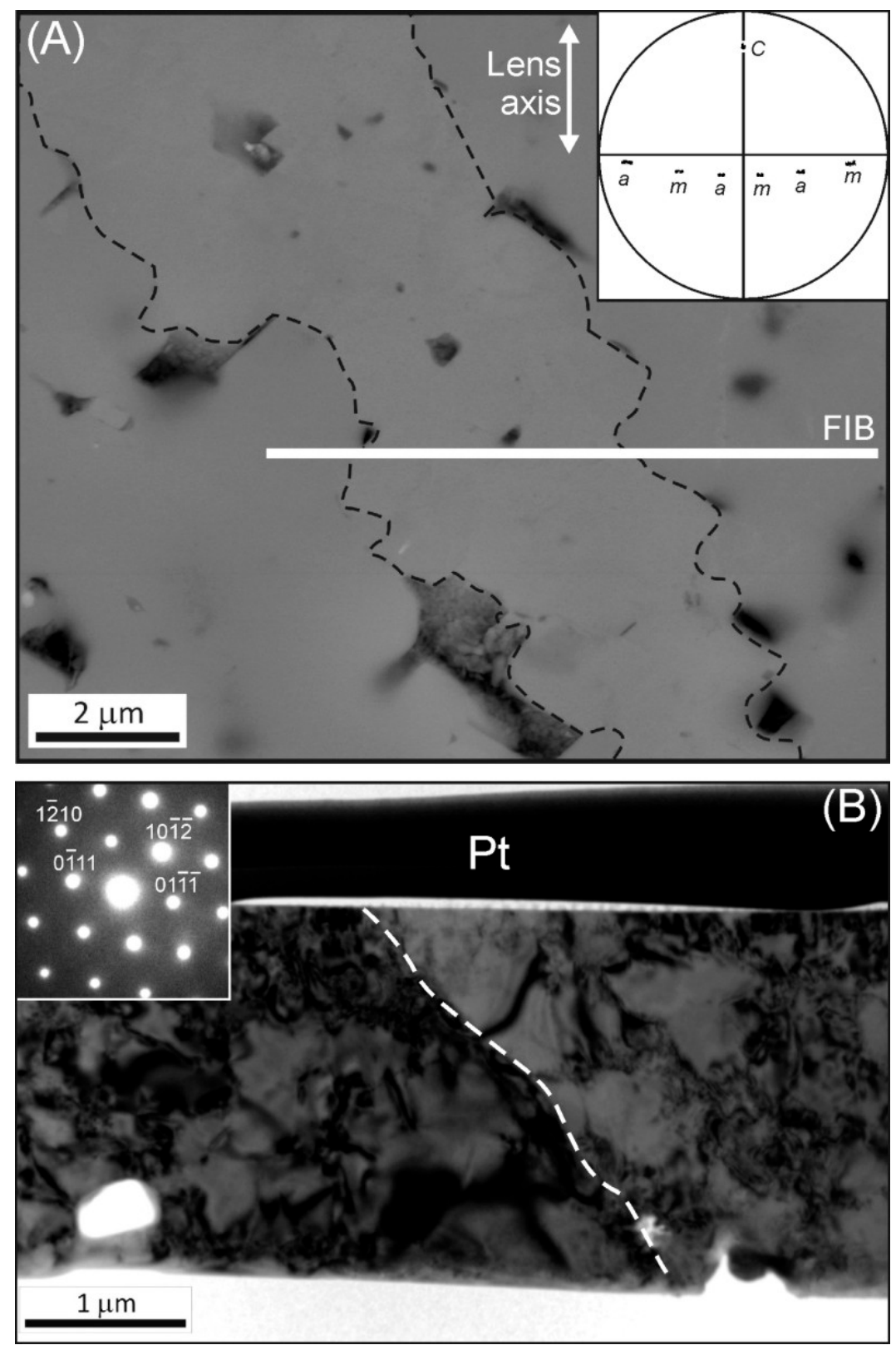

FIG. 5. Dalmanites sp. GLAHM 152332, Silurian, locality not known. Images of trabeculae in an intermediate PLA thin section of a lens. (A) BSE image of trabeculae close to the base of the lens. Trabecular boundaries are delineated by dashed black lines and the angular black areas are micropores. The calcite $c$ axis and the lens axis are both oriented north-south relative to the image. The white bar marks the plane of a foil that was cut from the thin section using the FIB technique. The inset pole figure shows the orientation of calcite in this field of view as determined by EBSD. $c, a$ and $m$ denote the orientation of the $c$ axis, the $a$ axes and poles to $\{10 \overline{1} 0\}$ planes respectively. Each of the ' $a$ ' and ' $m$ ' datapoints are in fact two closely spaced pairs of points reflecting the fact that adjacent trabeculae are related by rotation about the $c$ axis. (B) Bright-field TEM image of the foil that was cut through the trabeculae in (A). Its midplane is inclined at $17^{\circ}$ to (0001). The corresponding [21 $\left.\overline{3} 1\right]$ SAED pattern is inset. One of the trabecular boundaries is present (delineated by a dashed white line) and is oriented at $\sim 50^{\circ}$ to the thin section surface (on which the platinum (Pt) strap was deposited) and lies parallel to the traces of the (10 $\overline{1} \overline{2})$ plane and the $a$ axis. 


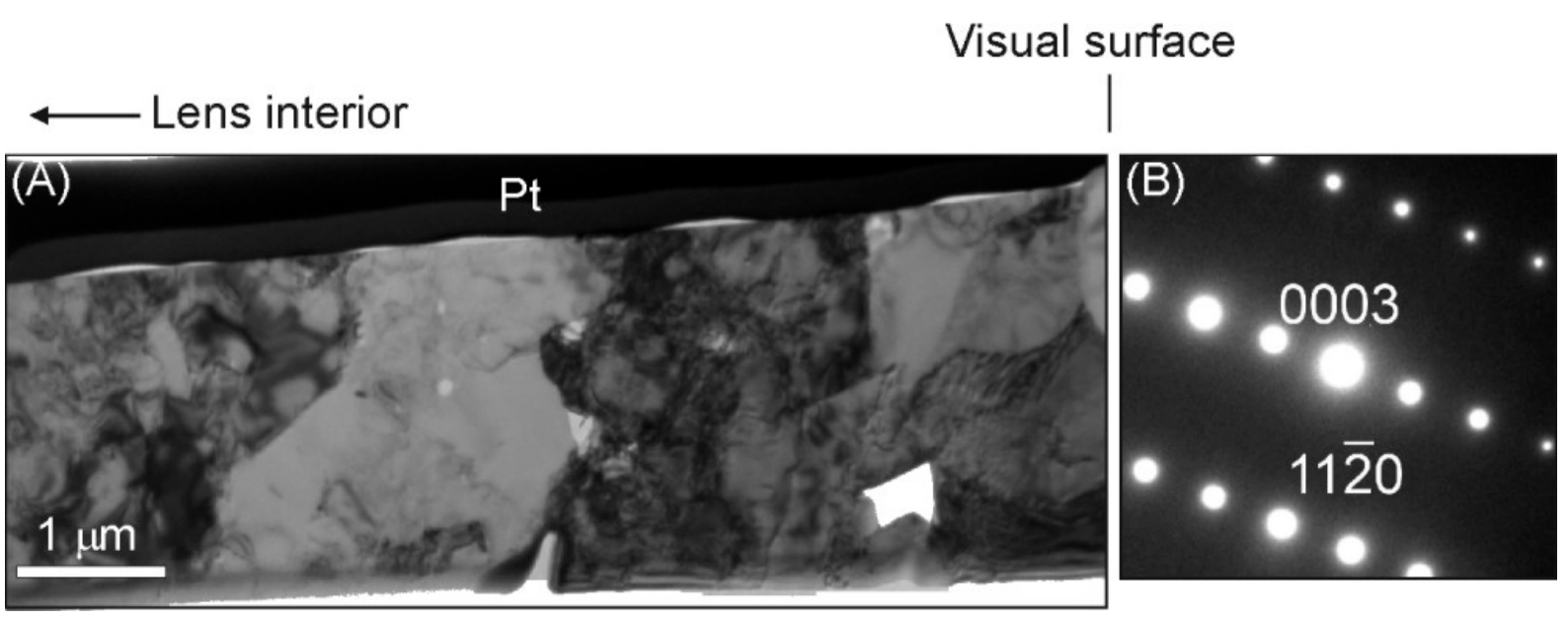

FIG. 6. Dalmanites sp. GLAHM 152332, Silurian, locality not known. TEM results from the radial fringe of one lens. (A) Bright-field TEM image of a foil cut from the radial fringe. The midplane of the foil is parallel to the lens axis. The radial fringe is composed of several elongate calcite subgrains that are distinguished by slight differences in crystallographic orientation (shown in the image as differences in greyscale). Subgrain boundaries are faceted and the angular white areas are micropores. Pt denotes the platinum strap that was deposited on the thin section surface prior to ion milling. (B) A [1100] SAED pattern obtained from one of the subgrains, which demonstrates that their boundaries are parallel to the trace of (0003) planes and to one of the $a$ axes (i.e. the normal to (1120)). The white angular area is a micropore. 

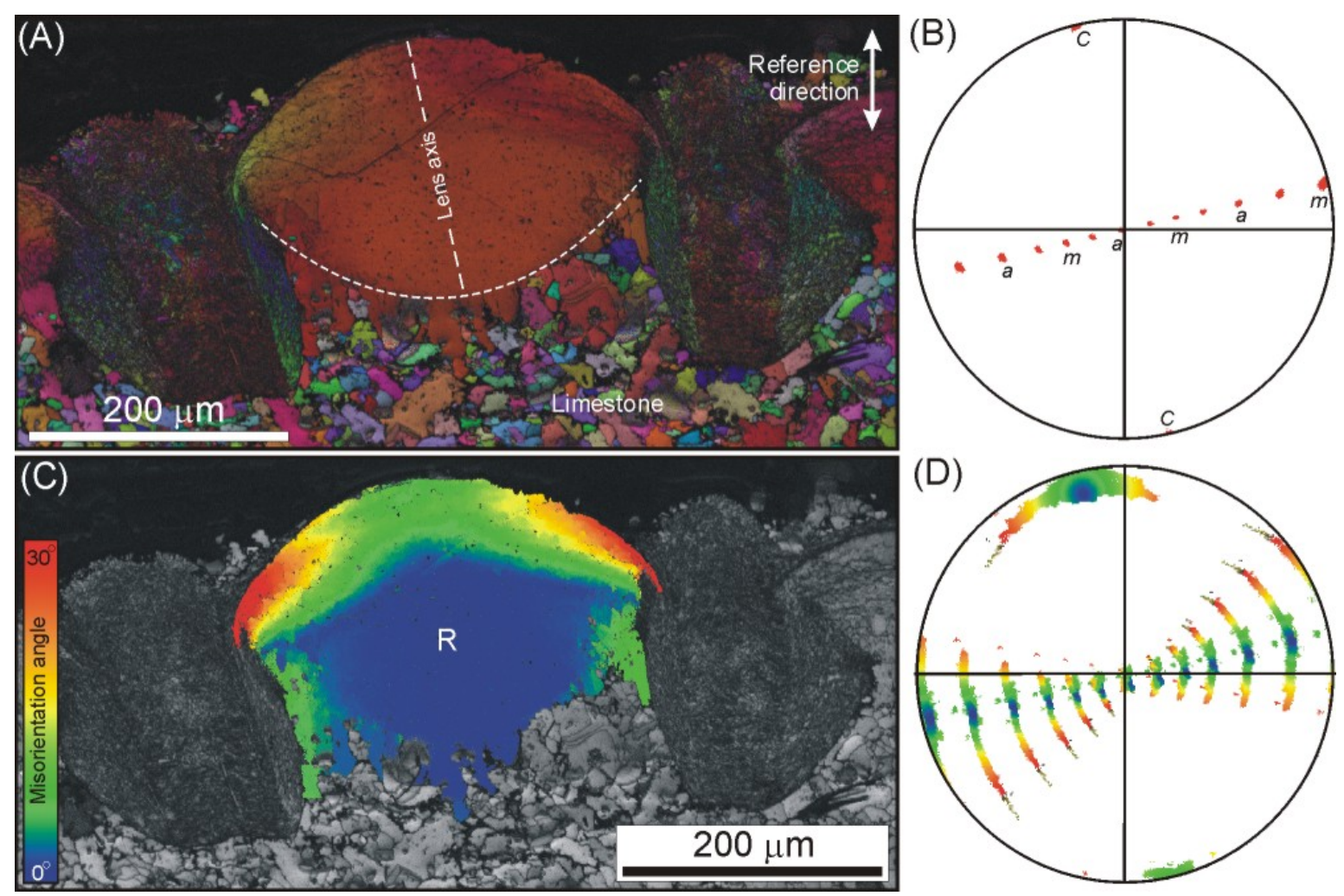

FIG. 7. Geesops schlotheimi (Bronn), GLAHM 152334/2, Ahrdorf Fm. (Eifelian), GeesGerolstein, Eifel, Germany. EBSD results from a lens in a PLA thin section cut in the H-2 position. (A) An IPF map overlain on an IQ map of a lens, its adjacent sclera and limestone. The edges of two neighbouring lenses are visible on the left and right hand margins of the image. Most of the lens calcite is oriented with its $c$ axis parallel to the reference direction. The radial fringe contains faint growth lines that follow the profile of the visual surface. The base of the lens (delineated by a dashed white line) has a syntaxial calcite overgrowth. (B) Pole figure showing the orientation of calcite in the centre of the lens in (A). $c$ denotes the $c$ axis, $a$ denotes the $a$ axis, $m$ denotes the pole to $\{10 \overline{1} 0\}$, and the unlabelled points are the poles to $\{4 \overline{1} \overline{3} 0\}$ planes. (C) Orientation tolerance map overlain on an IQ map of the lens in (A) showing that all of the lens calcite is within $30^{\circ}$ of the reference point (R). (D) Pole figure of the whole lens in (C) and with the same colour coding. The labelling of the datapoints is the same as in (B). The pole figure shows that most of the changes in crystallographic orientation within the radial fringe can be described by rotation about the $a$ axis (i.e. the centre of the pole figure) and the rotation is asymmetric (i.e. a slightly greater rotation anticlockwise as the image is printed). 

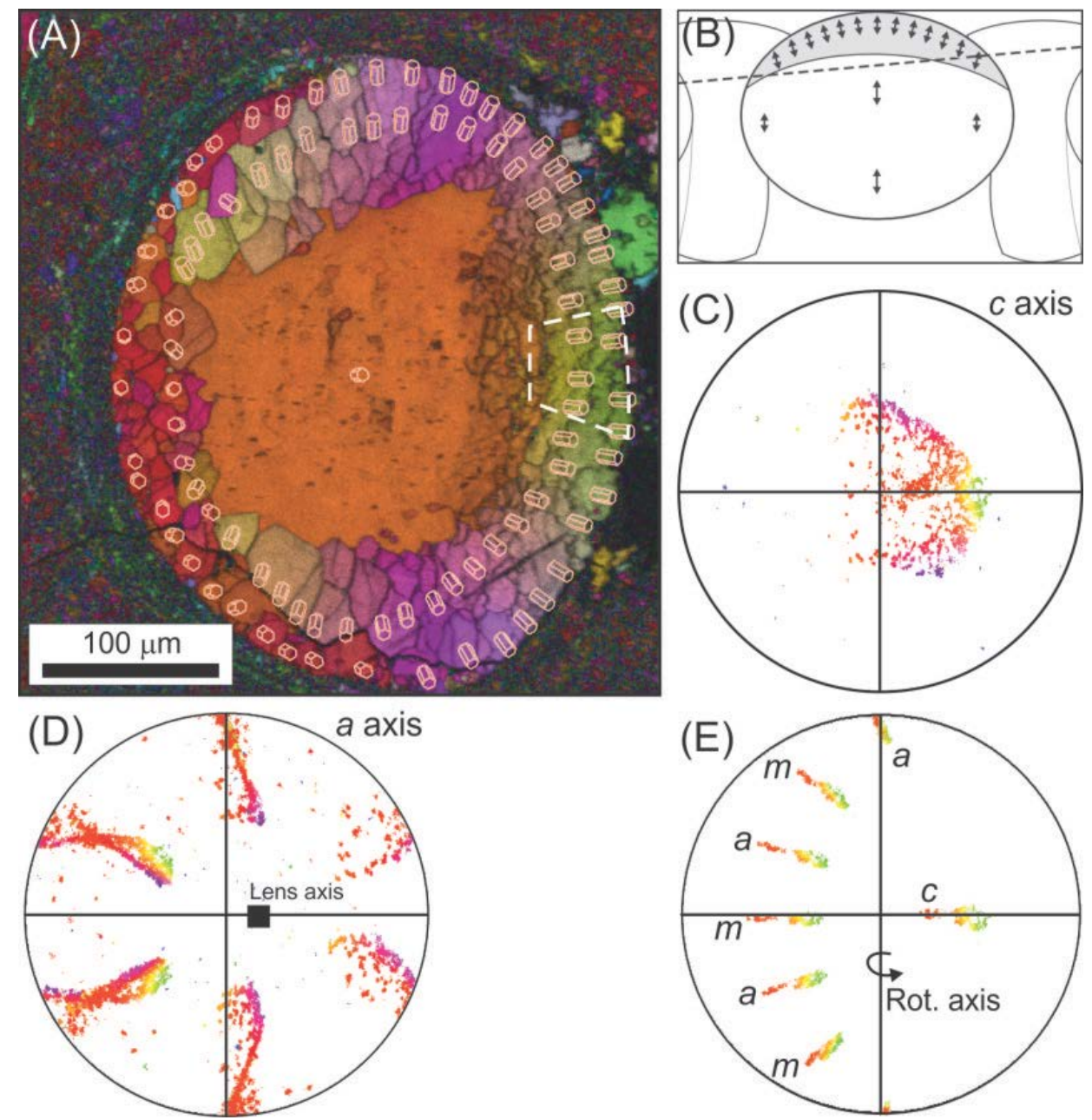

FIG. 8. Geesops schlotheimi (Bronn), Ahrdorf Fm. (Eifelian), Gees-Gerolstein, Eifel, Germany. Thin section missing but specimen from which it was cut remains,

GLAH152335/1, 2. EBSD results from a lens in a NLA thin section. (A) An IPF map overlain on an IQ map of the lens and enclosing sclera. The reference direction for the IPF colouring is normal to the plane of the page. All of the calcite in the centre of the lens is oriented with its $c$ axis parallel to the lens axis. Around the lens edge is the radial fringe, which is composed of subgrains, each a few tens of micrometres in size. The orientation of the calcite $c$ axis has been highlighted using the crystal model overlays and these demonstrate that within the radial fringe the $c$ axis fans out and away from the lens axis in all directions. (B) Schematic diagram showing the orientation of the plane of the thin section in (A) relative to the lens. The lens has been sectioned part way through the radial fringe and at $73^{\circ}$ to the lens axis. Double headed arrows indicate the orientation of the $c$ axis of lens calcite. (C) and (D) are pole figures showing the orientation of the calcite $c$ axis and $a$ axes respectively throughout the lens in (A) and using the same colour coding. The fact that the $a$ axis datapoints in (D) form lines radiating from the lens axis shows that there is no rotation about the $c$ axis. (E) Pole figure of a segment of the radial fringe that is enclosed within the dashed white lines in (A). Within this figure is plotted the $c$ axis $(c)$, the $a$ axes $(a)$ and poles to $\{10 \overline{1} 0\}$ planes $(m)$. The figure demonstrates that calcite in this segment of the radial fringe is related by rotation about the $a$ axis that is oriented north-south relative to the image. 

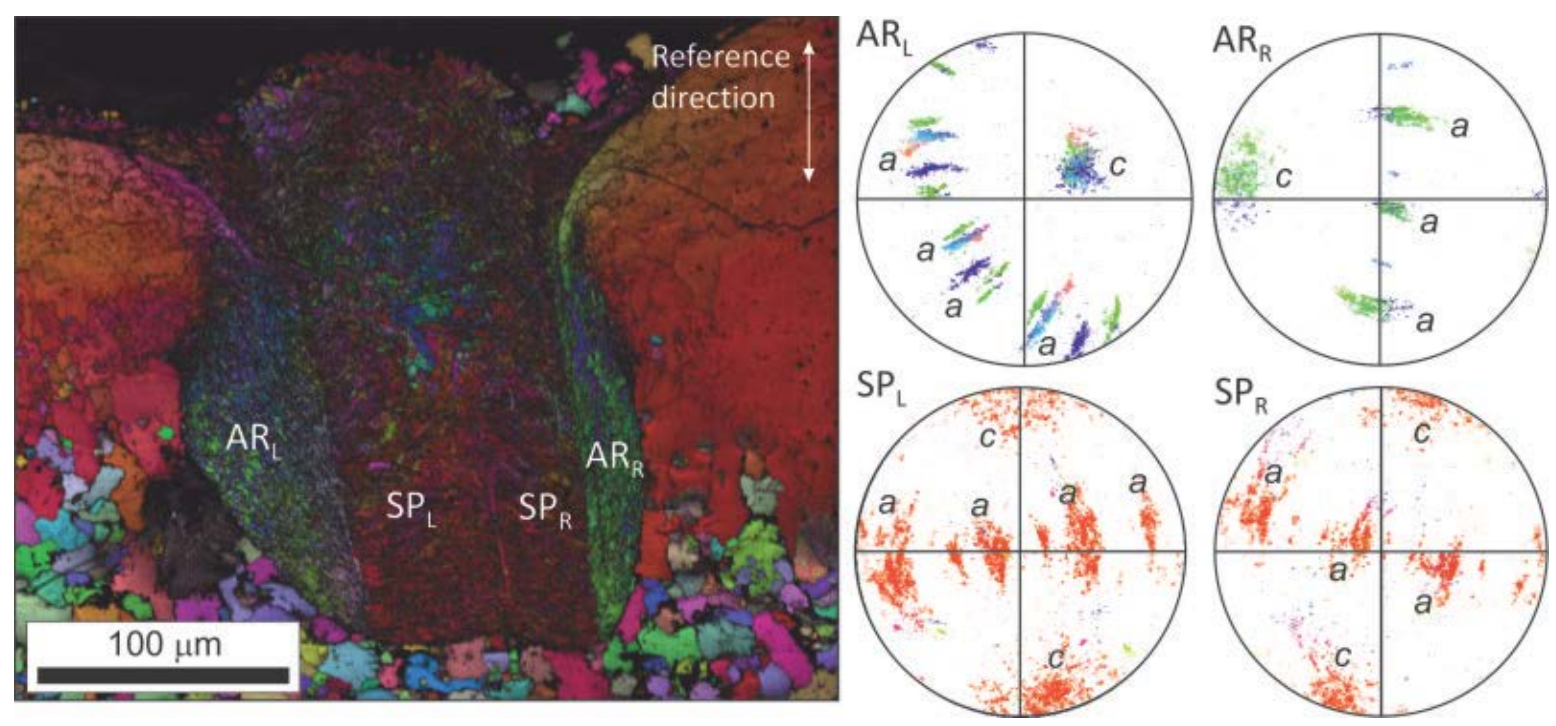

FIG. 9. Geesops schlotheimi (Bronn), GLAHM 152334/2, Ahrdorf Fm. (Eifelian), GeesGerolstein, Eifel, Germany. EBSD results from the sclera in a PLA thin section that was cut parallel to H-2. The map (IPF overlain on IQ) highlights the subdivision of the sclera into the scleral pillar (SP) and alveolar ring (AR). The pole figures show the orientation of the $a$ axes and $c$ axis (labelled $a$ and $c$ respectively) of calcite in the left hand side and right hand side alveolar rings ( $\mathrm{AR}_{\mathrm{L}}$ and $\mathrm{AR}_{\mathrm{R}}$ respectively) and in the left hand side and right hand side scleral pillars $\left(\mathrm{SP}_{\mathrm{L}}\right.$ and $\mathrm{SP}_{\mathrm{R}}$ respectively). Datapoints have the same colour coding as calcite in the IPF map. $c$ denotes the $c$ axis, $a$ denotes the $a$ axis. 

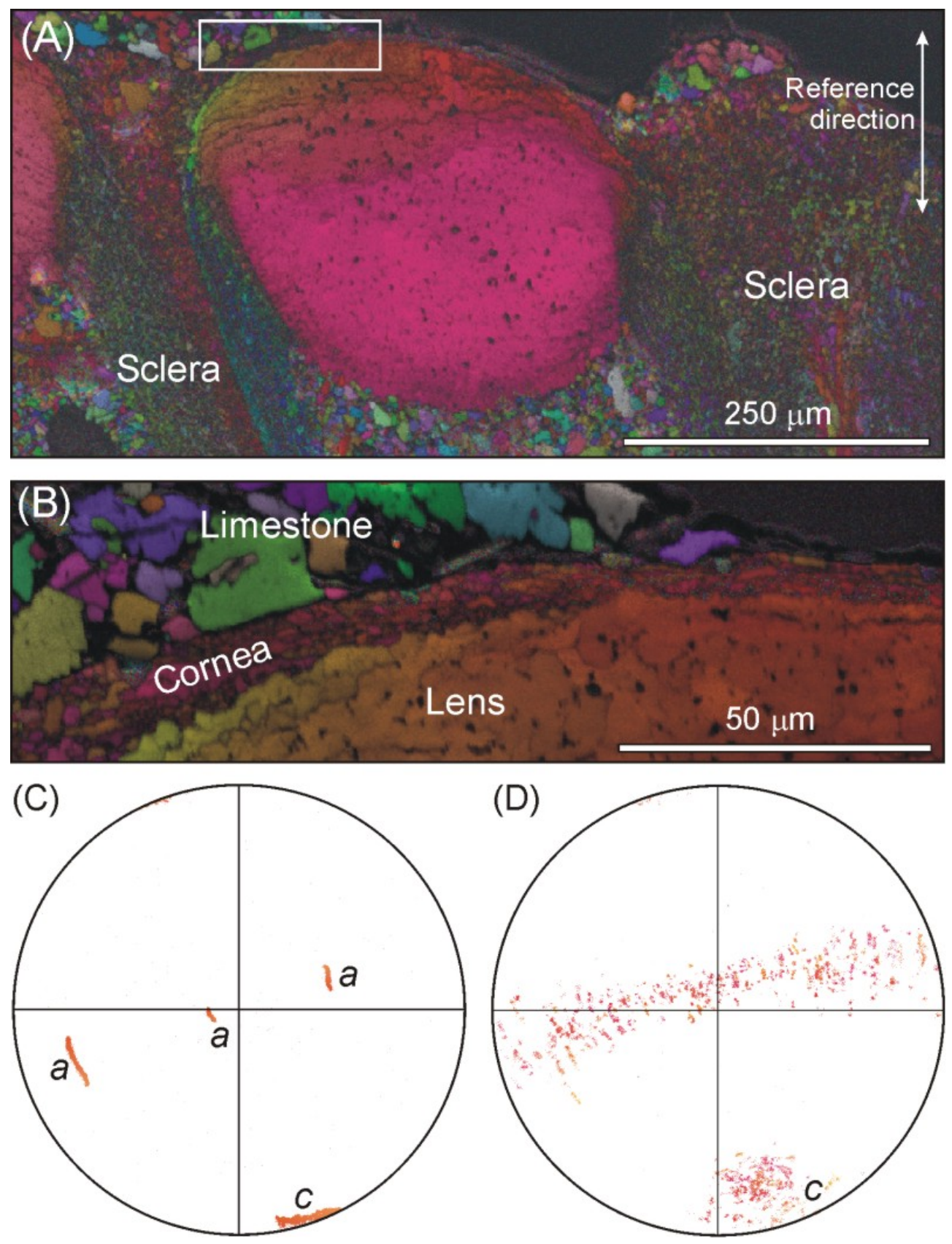

FIG. 10. Barrandeops forteyi McKellar and Chatterton, NHM It 29000, from the Lower Eifelian near Erfoud, southern Morocco. EBSD results from a lens in an intermediate PLA thin section. (A) An IPF map overlain on an IQ map of a lens, the sclera and enclosing limestone. (B) Map of the outermost part of the lens in (A) and its cornea (the area within the white rectangle in (A)). (C) Pole figure showing the orientation of lens calcite in (B) and with the same colour coding. The $a$ axes and $c$ axis are labelled $a$ and $c$ respectively. (D) Pole figure showing the orientation of corneal calcite in (B) and with the same colour coding. The $c$ axis is labelled $c$ and the array of points at a shallow angle to the equator of the figure are the $a$ axes. 

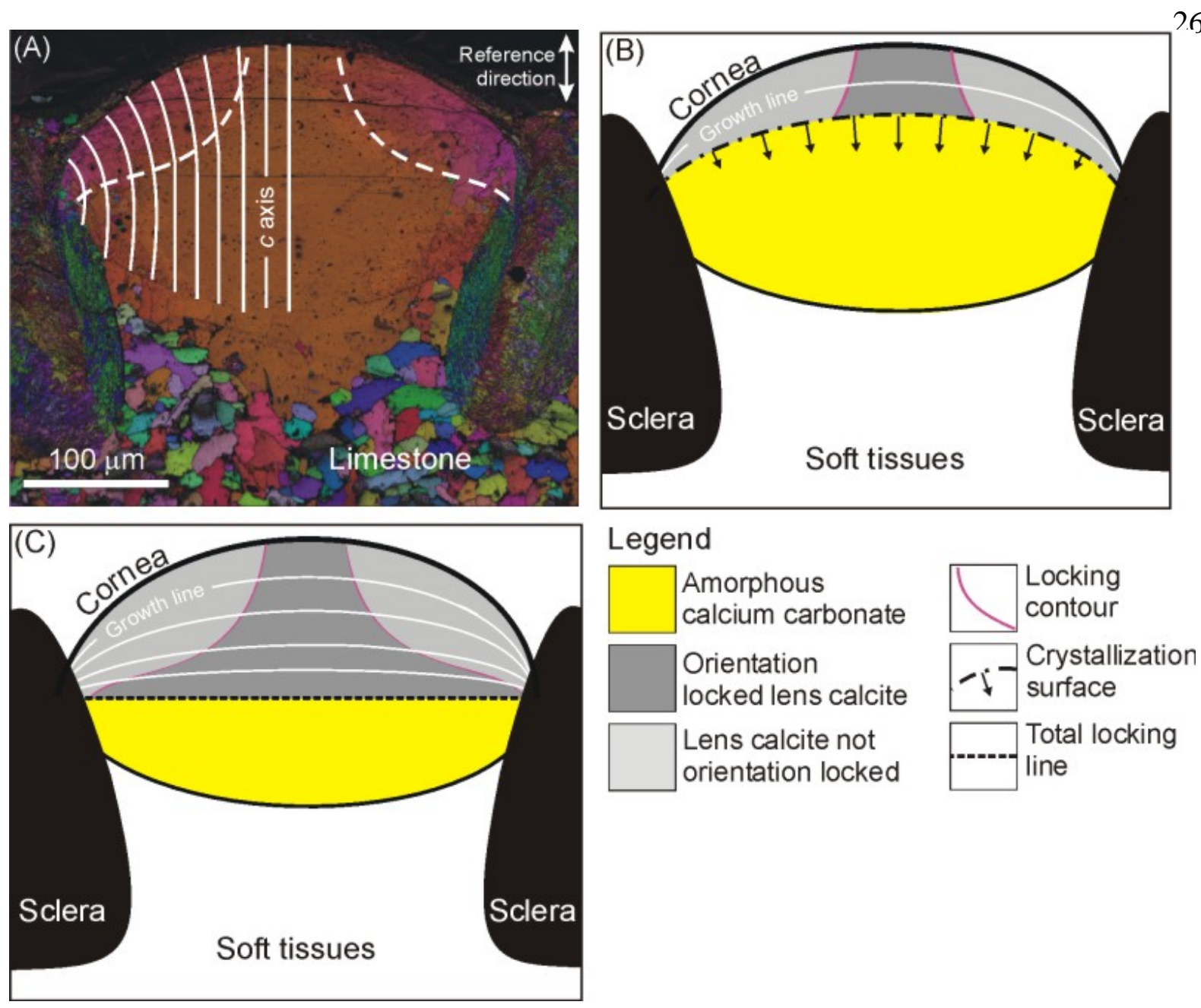

FIG. 11. Geesops schlotheimi (Bronn), GLAHM 152334/2, Ahrdorf Fm. (Eifelian), GeesGerolstein, Eifel, Germany. EBSD map and crystallisation model. (A) IPF map overlain on an IQ map of a lens in a diagonal PLA thin section. The orientation of the calcite $c$ axis in the left hand part of the lens is indicated by solid while lines. The point beneath the visual surface where the $c$ axis starts to curve away from the lens axis (i.e. the locking contour and the base of the radial fringe) is delineated by dashed white lines. (B) and (C) Diagrams of the lens in (A) illustrating the sequence in which it formed. (B) Lens calcite develops by crystallization of amorphous calcium carbonate along a surface advancing from the cornea, and growth lines mark its former position. Lens calcite thickens at a rate that is proportional to the curvature of the crystallization surface at any one point (illustrated by the black arrows). As the crystal lattice of calcite along the crystallization surface lines up, it becomes orientation locked, and the point in the lens where this happens is delineated by the locking contour. (C) By the time that the crystallization surface is horizontal, calcite along its entire length has locked (denoted by the total locking line, TLL). The crystallization surface becomes concave as it advances towards the base of the lens (not shown), and calcite may or may not remain crystallographically locked. 


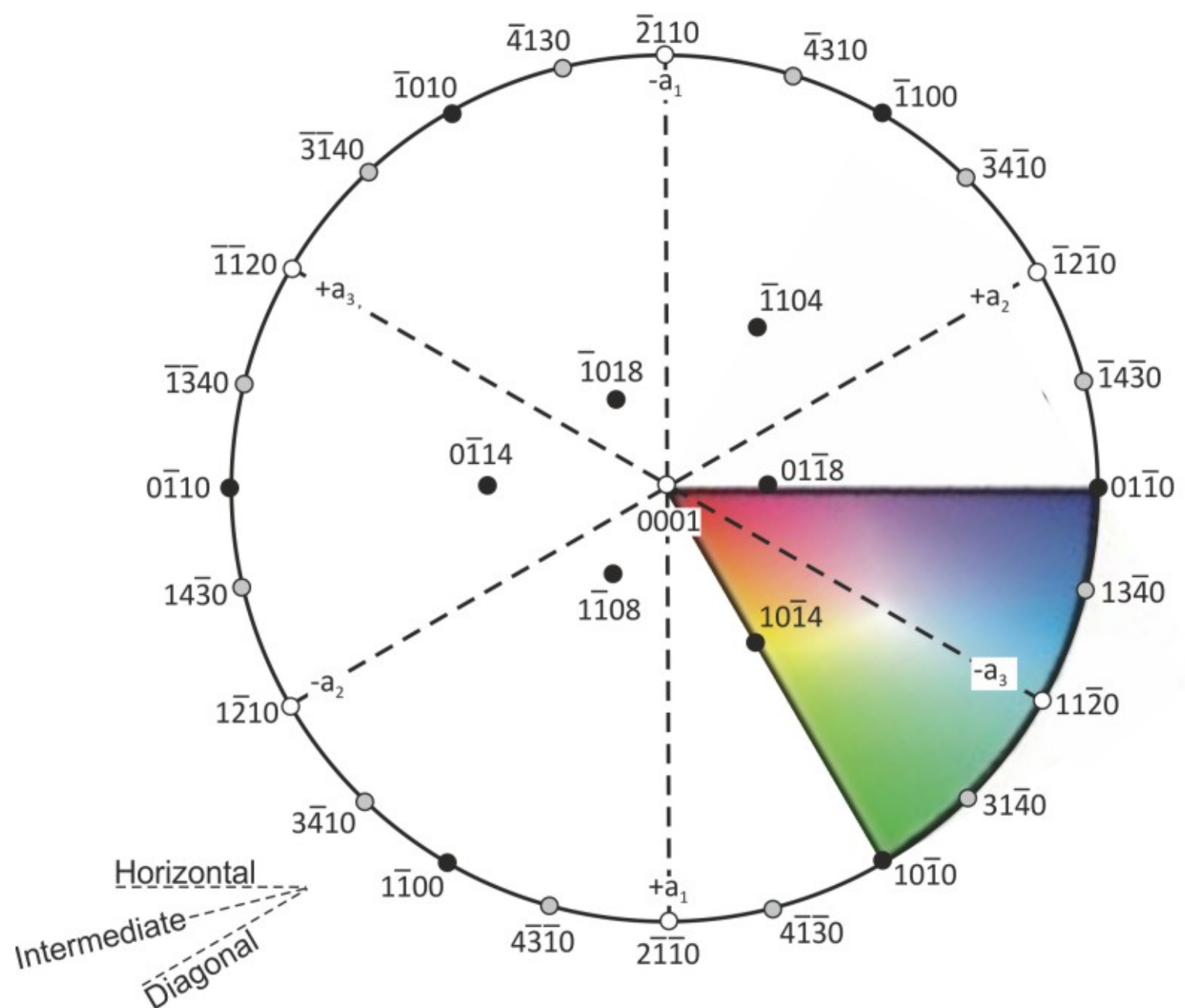

APPPENDIX S1. Stereographic projection (upper hemisphere) of calcite in the same orientation as calcite along the axes of lenses in Fig. 2. Plotted are the planes of interest in this study. Although the $\mathrm{a}_{1}$ axis is here oriented north-south (i.e. normal to the paraprebral lobe), designation of the $\mathrm{a}_{1}, \mathrm{a}_{2}$ and $\mathrm{a}_{3}$ axes is arbitrary. Indicated in the lower left are the PLA thin section orientations; the plane of the NLA thin sections is in the plane of the page. The coloured segment shows the colour coding of EBSD inverse pole figure (IPF) maps. For example, calcite that is oriented with its $c$ axis parallel to the reference direction will be coloured red in the IPF map whereas calcite oriented with one of its $a$ axes (i.e. poles to $\{2 \overline{1} \overline{1} 0\}$ planes) parallel to the reference direction will be turquoise. For clarity, only one of the six coloured segments that should occupy the entire stereographic projection has been shown. 